\title{
Astigmatism correction and corneal aberrations variability between two locations of cap side-cut after small incision lenticule extraction: a randomized study
}

\author{
Ming Zhang ( $\square$ zhangmingscu0905@163.com ) \\ Sichuan University \\ Wen Yang \\ Sichuan University \\ Junfeng Yang \\ Xinanjiaotong University \\ Juan Guo \\ Xinanjiaotong University
}

Zhiyu Shu

Xinanjiaotong University

Lei Song

Xinanjiaotong University

Ling Chen

Xinanjiaotong University

Yanliang Jiang

Xinanjiaotong University

\section{Research Article}

Keywords: small incision lenticule extraction (SMILE), cap side-cut (CSC), corneal aberration, coma aberration, astigmatism correction

Posted Date: March 7th, 2022

DOI: https://doi.org/10.21203/rs.3.rs-1404532/v1

License: (c) (i) This work is licensed under a Creative Commons Attribution 4.0 International License. Read Full License 


\section{Abstract}

Purpose To investigate astigmatism correction and the effect on corneal aberrations between two locations of the cap side-cut (CSC) after small incision lenticule extraction(SMILE) surgery.

Methods In this randomized, prospective research, 91 eyes of 49 patients were investigated after SMILE. The eyes were randomized into two groups with different CSC locations. The location was set at $120^{\circ}$ for group 1 and $90^{\circ}$ for group 2 . Uncorrected distant vision acuity (UDVA) and corrected distant vision acuity measurements, manifest refraction, and imaging were performed before and after surgery.

Results At the 3-month follow-up, all eyes in both groups had a postoperative UDVA $\geq 20 / 20$. There was no significantly difference in the refraction data nor in the safety and efficacy indices between the two groups ( $P=0.343$ and $P=0.738$, separately). The effects on corneal astigmatism, corneal root mean square high-order aberration, corneal spherical aberration, and corneal coma aberration at $0^{\circ}$ and $90^{\circ}$ showed no difference between the two groups.

Conclusions Astigmatic correction was not influenced by two locations of the CSC in SMILE surgery. No significant difference was found in visual and corneal optical quality results with two different CSCs in SMILE surgery.

\section{Introduction}

More than $90 \%$ of refractive surgeries are performed on the cornea. Of these, the small-incision lenticule extraction (SMILE) surgery is a popular one. A femtosecond laser is utilized to scan the lenticule in the corneal stroma, and the lenticule is taken out through a miniature incision; the entire operation process is in a closed mode. Milder postoperative reactions ${ }^{1}$, less nerve damage, quicker nerve recovery ${ }^{2,3}$ and milder dry eye symptoms ${ }^{4}$ greatly improve the safety and comfort of SMILE surgery.

The location of the cap side-cut (CSC) through which the lenticule is extracted can be determined individually ${ }^{5,6}$. Most investigations revealed a cap thickness of 100-150 microns and CSC length of 2-5 millimeter in the $90^{\circ}$ and $120^{\circ}$ directions ${ }^{7,8}$. Whether the direction of the CSC influences astigmatism correction or anterior corneal high-order aberration (HOA) requires verification. As far as we know, studies $^{9-11}$ have reported the refractive and keratometric outcomes of limbal relaxing incisions during cataract surgery, whereas few studies have investigated the influence of the location of the CSC on the refractive and optical outcomes after SMILE. We directed this randomized review to analyze the refractive and corneal optical quality results between two CSCs in SMILE surgery.

\section{Methods}

\section{Patients}


In this prospective, randomized research, 91 eyes of 49 patients (mean age of $22.73 \pm 5.36$ years) with myopic astigmatism were randomly assigned to two CSC groups by flipping a coin. Group 1 included 49 eyes (CSC on $120^{\circ}$ ) and group 2 included 42 eyes (CSC on 90 $)$. All patients underwent routine preoperative examinations and SMILE surgery between July 2021 and August 2021 at the Third People's Hospital of Chengdu.

Inclusion criteria were listed as following: age between 18-45 years; $\leq 0.50 \mathrm{D}$ increase in refraction in the past two years; abandoned soft contact lens use for 2 weeks), and no rigid contact lens use ( $\geq 3$ months). Exclusion criteria were as following: severe corneal opacity or cataract; ocular surface inflammation; uncontrolled glaucoma and fundus disease; , corneal thickness no more than $500 \mu \mathrm{m}$; abnormal corneal topography, and uncontrolled systemic diseases.

The investigation was approved by the Ethics Committee of the Third People's Hospital of Chengdu(No.2021-S-92)and was carried out conforming to the tenets of the Declaration of Helsinki. Informed consent was signed by every patient prior to the procedures.

\section{Examinations}

Preoperatively and 3 months postoperatively, routine ocular examinations, including slit-lamp biomicroscopy, manifest refraction, high-resolution Scheimpflug tomography, and intraocular pressure, uncorrected distance visual acuity (UDVA), and corrected distance visual acuity (CDVA) measurements, were performed by the same experienced optometrist. The following ophthalmological parameters were assessed: (1) UDVA, CDVA, manifest refraction; (2) vector analysis of astigmatism correction: targetinduced astigmatism vector (TIA), surgically induced astigmatism vector (SIA), correction index $(\mathrm{Cl})$, index of success (IOS), magnitude of error (MofE), and angle of error (AofE); and (3) anterior corneal astigmatism, corneal root mean square high-order aberration (RMS HOA), and corneal coma aberration (CA) at $0^{\circ}$ and $90^{\circ}$, determined using tomography on Pentacam tomography.

\section{Operation procedure}

All surgeries were accomplished by the same surgeon (W.Y.). After topical anesthesia, the surgeon performed SMILE utilizing the 500-kHz VisuMax femtosecond laser system (Carl Zeiss Meditec, Jena, Germany). The treatment parameters were as follows: with a cap diameter of 7.5 millimeter; with a cap thickness of 120 microns; with a lenticule diameter of 6.5 millimeter (with a transition zone of $0.1 \mathrm{~mm}$ ); CSC was performed at $90^{\circ}$ ( 12 o'clock) or $120^{\circ}$ (11 o'clock) with a $2 \mathrm{~mm}$ length. After femto-second laser scanning, the lamellar lenticule was carefully isolated with a slight obtuse spatula and grasped with a couple of forceps through the $2 \mathrm{~mm}$ CSC. Postoperatively, the patient was prescribed an antibiotic and steroid eye drop to use four times a day for 14 days.

\section{Statistical analysis}

Data were analyzed by utilising the Statistical Package for the Social Sciences (SPSS version 23.0, IBM). Values were totally expressed as mean \pm standard deviation(SD). Astigmatism correction was analyzed by vector analysis according to the Alpins method ${ }^{12}$. The Shapiro-Wilk test was utilized to test if the 
values follow a normal distribution. Normally distributed variables were tested by the Welch t-test, and non-normally distributed variables were detected by the Mann-Whitney $U$ test. P-value $<0.05$ was viewed as statistically significant.

\section{Results}

In total, 91 eyes of 49 patients were investigated in this research. The CSC was performed at $120^{\circ}$ peripherally in group 1 and $90^{\circ}$ in group 2. All eyes underwent an uneventful SMILE without any complication. No significant difference were revealed in the clinical and optical parameters before and 3 months after SMILE between the two groups (Table 1).

Table 1

The clinic parameters between two groups before and 3 months after surgery

\begin{tabular}{|c|c|c|c|c|c|c|}
\hline & \multicolumn{3}{|l|}{ Pre-op } & \multicolumn{3}{|c|}{3 months Post-op } \\
\hline & Group 1 & Group 2 & $\begin{array}{l}\text { P } \\
\text { Value }\end{array}$ & Group 1 & Group 2 & P Value \\
\hline UDVA & $1.13 \pm 0.178$ & $1.140 \pm 0.205$ & 0.927 & $\begin{array}{l}-0.092 \pm \\
0.049\end{array}$ & $\begin{array}{l}-0.083 \pm \\
0.054\end{array}$ & 0.532 \\
\hline CDVA & $\begin{array}{l}-0.096 \pm \\
0.041\end{array}$ & $\begin{array}{l}-0.079 \pm \\
0.047\end{array}$ & 0.150 & $\begin{array}{l}-0.102 \pm \\
0.038\end{array}$ & $\begin{array}{l}-0.098 \pm \\
0.047\end{array}$ & 0.593 \\
\hline Sphere & $\begin{array}{l}-4.760 \pm \\
1.338\end{array}$ & $\begin{array}{l}-4.970 \pm \\
1.257\end{array}$ & 0.443 & $\begin{array}{l}-0.112 \pm \\
0.275\end{array}$ & $\begin{array}{l}-0.101 \pm \\
0.265\end{array}$ & 0.464 \\
\hline Cylinder & $\begin{array}{l}-0.898 \pm \\
0.582\end{array}$ & $-0.86 \pm 0.446$ & 0.747 & $\begin{array}{l}-0.209 \pm \\
0.299\end{array}$ & $-0.25 \pm 0.297$ & 0.557 \\
\hline SE & $\begin{array}{l}-5.209 \pm \\
1.430\end{array}$ & $-5.40 \pm 1.269$ & 0.498 & $\begin{array}{l}-0.008 \pm \\
0.286\end{array}$ & $\begin{array}{l}-0.024 \pm \\
0.301\end{array}$ & 0.488 \\
\hline \multicolumn{7}{|c|}{$\begin{array}{l}\text { Pre-op: Pre operation, Post-op: Post operation, UDVA: Uncorrected Distance Visual Acuity, CDVA: } \\
\text { Corrected Distance Visual Acuity, }\end{array}$} \\
\hline \multicolumn{7}{|c|}{ SE: Spherical Equivalent } \\
\hline${ }^{*} \mathrm{P}<0.05$ & statistically si & ficant & & & & \\
\hline
\end{tabular}

\section{Safety and efficacy}

At the 3-month follow-up visit, the efficacy and safety indices were $1.00 \pm 0.08$ and $1.01 \pm 0.06$ in group 1 and $1.02 \pm 0.14$ and $1.04 \pm 0.14$ in group 2 , respectively. We detected no significant differences in the safety and efficacy indices between the two groups $(P=0.343$ and $P=0.738$, respectively). A decline in CDVA was showed in six eyes, whereas all eyes had a UDVA $\geq 20 / 20$ after the surgery. Furthermore, $88 \%$ of the eyes (80 eyes) had better follow-up UDVA than preoperative CDVA, and 14 eyes gained at least one line. 


\section{Vector analysis}

The vector analysis of astigmatism correction in the two groups are recorded in Table 2 . The $\mathrm{Cl}$ was $1.028 \pm 0.384$ in group 1 and $1.043 \pm 0.516$ in group 2 . The MofE was $-0.045 \pm 0.245$ and $-0.018 \pm 0.262$ in groups 1 and 2, respectively. The AofE was $-0.630 \pm 9.639$ in group 1 and $-2.710 \pm 13.994$ in group 2 , and the values within -15 to $15^{\circ}$ were $85.71 \%$ and $83.33 \%$ in the eyes of group 1 and group 2 , separately. No significant differences were detected between the two groups. The IOS in group 1 was lower than that in group 2, however, no significant difference was detected $(P=0.09)$. Single-angle plots introducing the comparison of the TIA, SIA, DV and Cl for astigmatism correction between the two groups are shown in Fig. 1. The DV in Group $2(0.327 \pm 0.161)$ was higer than that in Group $1(0.255 \pm 0.188)$. However, no significantly difference was detected $(P=0.105)$, no significant difference were observed between the two groups in TIA, SIA and $\mathrm{Cl}$ neither $(P=0.820,0.839,0.971)$. The Scatterplots and the linear regression analysis between the SIA and TIA after SMILE surgery in group 1 and group 2 are shown in Fig. 2 . The predictability of cylinder correction was excellent, $95 \%$ of eyes were within $\pm 0.50 \mathrm{D}$, whereas all eyes were within $\pm 1.00 \mathrm{D}$ of astigmatism correction. The predictability was slightly better in the Group 2 (average deviation: -0.02 D) versus the Group 1 (average deviation: -0.04 D), However, no significant difference was observed $(P=0.538)$.

Table 2

Vector parameters of refraction astigmatism between two groups

\begin{tabular}{|llll|}
\hline & Group 1 & Group 2 & P Value \\
\hline TIA & $0.785 \pm 0.493$ & $0.756 \pm 0.391$ & 0.820 \\
\hline SIA & $0.740 \pm 0.442$ & $0.738 \pm 0.385$ & 0.839 \\
\hline DV & $0.255 \pm 0.188$ & $0.327 \pm 0.161$ & 0.105 \\
\hline AofE & $-0.630 \pm 0.639$ & $-0.700 \pm 0.493$ & 0.914 \\
\hline MofE & $-0.045 \pm 0.245$ & $-0.018 \pm 0.161$ & 0.447 \\
\hline CI & $1.028 \pm 0.384$ & $1.043 \pm 0.516$ & 0.971 \\
\hline IOS & $0.365 \pm 0.311$ & $0.548 \pm 0.403$ & 0.09 \\
\hline COA & $1.099 \pm 0.380$ & $1.172 \pm 0.520$ & 0.978 \\
\hline FI & $0.974 \pm 0.372$ & $0.970 \pm 0.530$ & 0.965 \\
\hline $\begin{array}{l}\text { TIA = target-induced astigmatism; SIA = surgically induced astigmatism; DV = difference vector; AofE } \\
= \\
\text { congle of error; MofE = magnitude of error CI = correction index; IOS = index of success; COA = }\end{array}$ & \\
\hline *P $<0.05=$ statistically significant & & \\
\hline
\end{tabular}

\section{Corneal aberrations}


The values of anterior corneal astigmatism (ACA) and CA before the surgery and 3 months postoperatively are shown in Table 3. No statistically significant difference was found in the preoperative and postoperative ACA between the group 1 and group 2; furthermore, the changes in ACA in the group 1 and group 2 had no significant difference $(P=0.747,0.930$, and 0.768 , respectively). There was significant increase in RMS HOA, spherical aberration (SA), and coma in both groups after SMILE surgery $(P<0.05)$. Although the induced vertical coma $(V C)$ was higher than the induced horizontal coma $(H C)$ in both groups, no significant differences were found between the two groups. Moreover, no significant difference was found in surgically induced RMS HOA $(P=0.688), S A(P=0.497), H C(P=0.570)$, or VC ( $P$ $=0.732$ ).

Table 3

Comparisons of anterior corneal astigmatism and corneal wavefront aberrations between two groups

\begin{tabular}{|c|c|c|c|c|}
\hline & & Preop & Postop & Induced \\
\hline \multirow{5}{*}{$\begin{array}{l}\text { Group } 1 \\
(\mathrm{n}=49)\end{array}$} & ACA & $1.186 \pm 0.569$ & $0.598 \pm 0.350$ & $0.588 \pm 0.537$ \\
\hline & RMS HOA & $0.351 \pm 0.090$ & $0.734 \pm 0.256$ & $0.383 \pm 0.281$ \\
\hline & SA & $0.187 \pm 0.073$ & $0.349 \pm 0.189$ & $0.162 \pm 0.162$ \\
\hline & $\mathrm{HC}$ & $0.033 \pm 0.112$ & $0.137 \pm 0.278$ & $0.105 \pm 0.256$ \\
\hline & VC & $-0.031 \pm 0.174$ & $-0.430 \pm 0.307$ & $-0.398 \pm 0.290$ \\
\hline \multirow{5}{*}{$\begin{array}{l}\text { Group } 2 \\
(n=42)\end{array}$} & ACA & $1.124 \pm 0.565$ & $0.604 \pm 0.331$ & $0.520 \pm 0.497$ \\
\hline & RMS HOA & $0.352 \pm 0.073$ & $0.739 \pm 0.187$ & $0.387 \pm 0.199$ \\
\hline & SA & $0.191 \pm 0.082$ & $0.357 \pm 0.105$ & $0.166 \pm 0.102$ \\
\hline & $\mathrm{HC}$ & $0.019 \pm 0.121$ & $0.066 \pm 0.149$ & $0.048 \pm 0.141$ \\
\hline & VC & $-0.03 \pm 0.168$ & $-0.424 \pm 0.341$ & $-0.394 \pm 0.313$ \\
\hline \multirow{5}{*}{$\begin{array}{l}\text { P Value } \\
\text { (Group } 1 \text { vs } \\
\text { Group 2) }\end{array}$} & ACA & 0.747 & 0.930 & 0.768 \\
\hline & RMS HOA & 0.978 & 0.799 & 0.688 \\
\hline & SA & 0.956 & 0.504 & 0.497 \\
\hline & $\mathrm{HC}$ & 0.469 & 0.162 & 0.570 \\
\hline & VC & 0.943 & 0.880 & 0.732 \\
\hline
\end{tabular}

\section{Discussion}


To date, studies on SMILE have not determined the standard size or location for CSCs. Most studies ${ }^{13-15}$ have determined a $90^{\circ}$ direction for CSCs of $1.95 \mathrm{~mm}$ length. For patients with superior corneal pannus or extremely deep sockets, the surgeon may adjust the CSC direction to $120^{\circ}$ to avoid hemorrhage or ease the procedure. Dan et al. reported the design of two CSCs in the superior nasal and superior temporal directions in SMILE surgery for low myopia ${ }^{16}$. We performed this research to investigate the effects of the two CSC types on astigmatism correction and visual performance.

In this study, all eyes in both the two groups had a postoperative UDVA $\geq 20 / 20$ at the 3-month visit. The safety and efficacy index were $1.01 \pm 0.06$ and $1.00 \pm 0.08$ in group 1 and $1.04 \pm 0.14$ and $1.02 \pm 0.14$ in group 2, respectively. The safety index was close to that reported in previous studies ${ }^{17,18}$, which reported a median safety index of 1 and 1.1, respectively, at the 3-month follow-up after SMILE surgery. Another study ${ }^{19}$ reported an efficacy index of $1.18 \pm 0.21$, with a mean preoperative astigmatism of $-0.68 \pm 0.46 \mathrm{D}$, which was -0.82 . $\pm 0.52 \mathrm{D}$ in the current study. There were no differences in UDVA, CDVA, SE, safety, or efficacy index between the two groups. Our findings showed no difference in refraction outcomes between the two CSC groups.

Vector analysis revealed an average $\mathrm{Cl}$ of 1.028 and 1.043 in groups 1 and 2 , respectively $(P=0.971)$, which indicated a slight overcorrection of astigmatism in both groups. The average $\mathrm{Cl}$ in a previous study ${ }^{20}$ showed a similar value of 1.05 using SMILE surgery and 0.95 using laser epithelial keratomileusis. Although a lower IOS was found in group 1 ( 0.365 vs. $0.548, P=0.09)$, the difference was not significant, and the difference in ME between the two groups was not statistically significant $(P=$ 0.447), indicating no difference in residual astigmatism between the two groups. Chan et al. also concluded that there was no difference in astigmatism correction between two opening incisions ${ }^{21}$. In addition to the magnitude, it is important to correct astigmatism with a precise axis. Alpins noted that the deficiency of the correction effect is $13.4 \%$ when treatment is skewed by $15^{\circ}$ and is almost $50 \%$ when treatment is skewed by $30^{\circ} 22$. Xia et al. conducted that $77 \%$ of the eyes had $A E$ values between $-15^{\circ}$ and $15^{\circ 23}$. In this study, $85.71 \%$ and $83.33 \%$ of the eyes in group 1 and group 2 , separately, had AE values between -15 and $15^{\circ}$, which showed a slightly more accurate correction of astigmatism in group 1 ; however, no statistical significance was found between the two groups. The AE in group 1 was $-0.630 \pm$ 9.64 and in group 2 was $-2.710 \pm 13.99$; the less favorable range $\left(9.64^{\circ}\right.$ and $\left.13.94^{\circ}\right)$ occurred in both groups, suggesting some variable factors, such as healing or alignment, which require further investigation. No significant difference was detected in other variables by using vector analysis.

Corneal anterior surface aberrations account for $80 \%$ of aberrations in the eye and are the main factors influencing visual quality ${ }^{24,25}$. In the Zernike HOA chart, SA and coma are the most common parameters used to analyze the impact on visual quality ${ }^{26}$. Corneal anterior astigmatism and aberration variability were used in the present study. The change in corneal anterior astigmatism was greater in group 1 (0.588) than in group $2(0.520)$, but the difference was not statistically significant. Corneal aberrations, including RMS HOA, SA, HC, and VC increased after SMILE surgery. Several studies ${ }^{27-29}$ have reported increased HOA in both SMILE and laser-assisted in situ keratomileusis (LASIK). The induced VC was 
considerably higher than the induced $\mathrm{HC}$ in both groups $(P=0.447)$, and Chalita et al. reported that increased $\mathrm{HC}$ after LASIK surgery was correlated with double vision but not with increased $\mathrm{VC}^{30}$. No significant difference was discovered in the induced RMS HOA, SA, HC, or VC between the two groups.

A limitation of our investigation is that the 3-month follow-up may be not adequate to evaluate astigmatic correction and vision quality in the two different directions of CSCs. Studies with longer follow-up durations and more directions of CSCs are needed to confirm the results of the present study.

\section{Conclusions}

we found no significant differences in visual and corneal optical quality results in two different directions of CSC during SMILE surgery. Surgeons can choose either of the two directions of CSC individually during SMILE surgery without affecting the visual outcome.

\section{Declarations}

\section{Acknowledgements}

No author reports any financial interest relevant to this study.

\section{Author contribution}

(I) Conception and design: M Zhang, W Yang, J,Yang; (II) Administrative support: M Zhang; (III) Provision of study materials or patients: M Zhang; (IV) Collection and assembly of data: W Yang; Z Shu (V) Data analysis and interpretation: W Yang, J Guo, Z Shu, L Song, L Chen, Y Jiang; (VI) Manuscript writing: All authors; (VI) Final approval of manuscript: All authors.

\section{Funding}

This study was financially supported in part by The Project of National Key Research and Development (grant no. 2018YFC1106103).

\section{Data Availability statement}

The datasets used and/or analyzed during the current study available from the corresponding author on reasonable request.

\section{Conflict of interest}

The authors declare no competing interests. 


\section{References}

1. Shah, R., Shah, S. \& Sengupta, S. Results of small incision lenticule extraction: All-in-one femtosecond laser refractive surgery. J Cataract Refract Surg. 37(1), 127-137 (2011).

2. Mohamed-Noriega, K. et al. Early corneal nerve damage and recovery following small incision lenticule extraction (SMILE) and laser in situ keratomileusis (LASIK). Invest Ophthalmol Vis Sci. 55(3), 1823-34 (2014).

3. Li, M. et al. Comparison of corneal sensation between small incision lenticule extraction (SMILE) and femtosecond laser-assisted LASIK for myopia. J Refract Surg. 30(2), 94-100 (2014).

4. Kobashi, H., Kamiya, K. \& Shimizu, K. Dry Eye After Small Incision Lenticule Extraction and Femtosecond Laser Assisted LASIK: Meta-Analysis. Cornea. 36(1), 85-91(2017).

5. Chansue, E., Tanehsakdi, M., Swasdibutra, S. \& McAlinden, C. Efficacy, predictability and safety of small incision lenticule extraction (SMILE). Eye Vis (Lond). 2, 14(2015).

6. Ivarsen, A., Asp, S. \& Hjortdal, J. Safety and complications of more than 1500 small incision lenticule extraction procedures. Ophthalmology. 121(4), 822-828(2014).

7. Chan, C., Lawless, M., Sutton, G., Versace, P. \& Hodge, C. Small incision lenticule extraction (SMILE) in 2015.Clin Exp Optom. 99(3), 204-12(2016).

8. Moshirfar, M. et al. Small incision lenticule extraction. J Cataract Refract Surg. 41(3), 652-65(2015).

9. Riaz, K.M. et al. Refractive and keratometric outcomes of supervised novice surgeon-performed limbal relaxing incisions: 1-year results. J Cataract Refract Surg. 47(10), 1319-1326 (2021).

10. Stanojcic, N. et al. A randomised controlled trial comparing femtosecond laser-assisted cataract surgery versus conventional phacoemulsification surgery: 12-month results. Br J Ophthalmol. 105(5), 631-638(2021).

11. Roberts, H.W., Wagh, V.K., Sullivan, D.L., Archer, T.J. \& O'Brart D.P.S. Refractive outcomes after limbal relaxing incisions or femtosecond laser arcuate keratotomy to manage corneal astigmatism at the time of cataract surgery. J Cataract Refract Surg. 44(8), 955-963(2018).

12. Alpins, NA. \& Goggin, M. Practical astigmatism analysis for refractive outcomes in cataract and refractive surgery. Surv Ophthalmol. 49(1), 109-122(2004).

13. Ganesh, S., Brar, S. \& Pawar, A. Results of intraoperative manual Cyclotorsion compensation for myopic astigmatism in patients undergoing small incision Lenticule extraction (SMILE). J Refract Surg. 33(8), 506-12 (2017).

14. Varsen, A., Gyldenkerne, A. \& Hjortdal, J. Correction of astigmatism with small-incision lenticule extraction: impact of against-the-rule and with-the-rule astigmatism. J Cataract Refract Surg. 44(9), 1066-72(2018).

15. Vestergaard, A., Ivarsen, A.R., Asp, S. \& Hjortdal, JØ. Small-incision lenticule extraction for moderate to high myopia: Predictability, safety, and patient satisfaction. J Cataract Refract Surg. 38(11), 2003-2010 (2012). 
16. Reinstein, D.Z., Carp, G.I., Archer, T.J. \& Gobbe, M. Outcomes of small incision lenticule extraction (SMILE) in low myopia. J Refract Surg. 30(12), 812-818(2014).

17. Hou, X. et al. Early visual quality outcomes after small-incision lenticule extraction surgery for correcting high myopic astigmatism. BMC Ophthalmol. 21(1), 48 (2021).

18. Ang, M., Farook, M., Htoon, HM. \& Mehta, J. Randomized Clinical Trial Comparing Femtosecond LASIK and Small-Incision Lenticule Extraction. Ophthalmology. 127(6), 724-730 (2020).

19. Miao, H. et al. Optical quality and intraocular scattering after femtosecond laser small incision lenticule extraction. J Refract Surg. 30(5), 296-302(2014).

20. Qian, Y., Huang, J., Xingtao, Zhou. \& Wang, Y. Comparison of femtosecond laser small-incision lenticule extraction and laser-assisted subepithelial keratectomy to correct myopic astigmatism. $J$ Cataract Refract Surg. 41(11), 2476-86(2015).

21. Chan,Tommy, C.Y. et al. Effect of location of opening incision on astigmatic correction after smallincision lenticule extraction. Sci Rep. 6: 35881(2016).

22. Alpins, N.A. Vector analysis of astigmatism changes by flattening, steepening, and torque. J Cataract Refract Surg. 23(10), 1503-14(1997).

23. Xia, F. et al. Four-Year Outcomes of Small Incision Lenticule Extraction for Extreme High Myopia and Myopic Astigmatism. Front Med (Lausanne). 7:575779(2020).

24. Buhren, J. et al. The effect of the asphericity of myopiclaser ablation profiles on the induction of wavefront aberrations. Invest Ophthalmol Vis Sci. 51(5), 2805-12(2010).

25. Wan, X.H. et al. Ocular monochromatic aberrations in a rural Chinese adult population. Optom Vis Sci. 91(1), 68-75(2014).

26. Atchison, D.A., Suheimat, M., Mathur, A., Lister, L.J. \& Rozema, J. Anterior corneal, posterior corneal, and lenticular contributions to ocular aberrations. Invest Ophthalmol Vis Sci. 57(13), 5263-70(2016).

27. Ye, M.J. et al. SMILE and wavefront guided LASIK out-compete other refractive surgeries in ameliorating the induction of high-order aberrations in anterior corneal surface. J Ophthalmol. 2016, 8702162 (2016).

28. Lee, H. et al. Comparing corneal higher-order aberrations in corneal wavefront-guided transepithelial photorefractive keratectomy versus small-incision lenticule extraction. J Cataract Refract Surg. 44(6), 725-733(2018).

29. Shetty, R. et al. Wavefront-guided LASIK has comparable ocular and corneal aberrometric outcomes but better visual acuity outcomes than SMILE in myopic eyes. J Refract Surg. 34(8), 527-532(2018).

30. Chalita, M.R., Chavala, S., Xu, M. \& Krueger, R.R. Wavefront analysis in post-LASIK eyes and its correlation with visual symptoms, refraction, and topography. Ophthalmology. 111(3), 447-53 (2004).

\section{Figures}



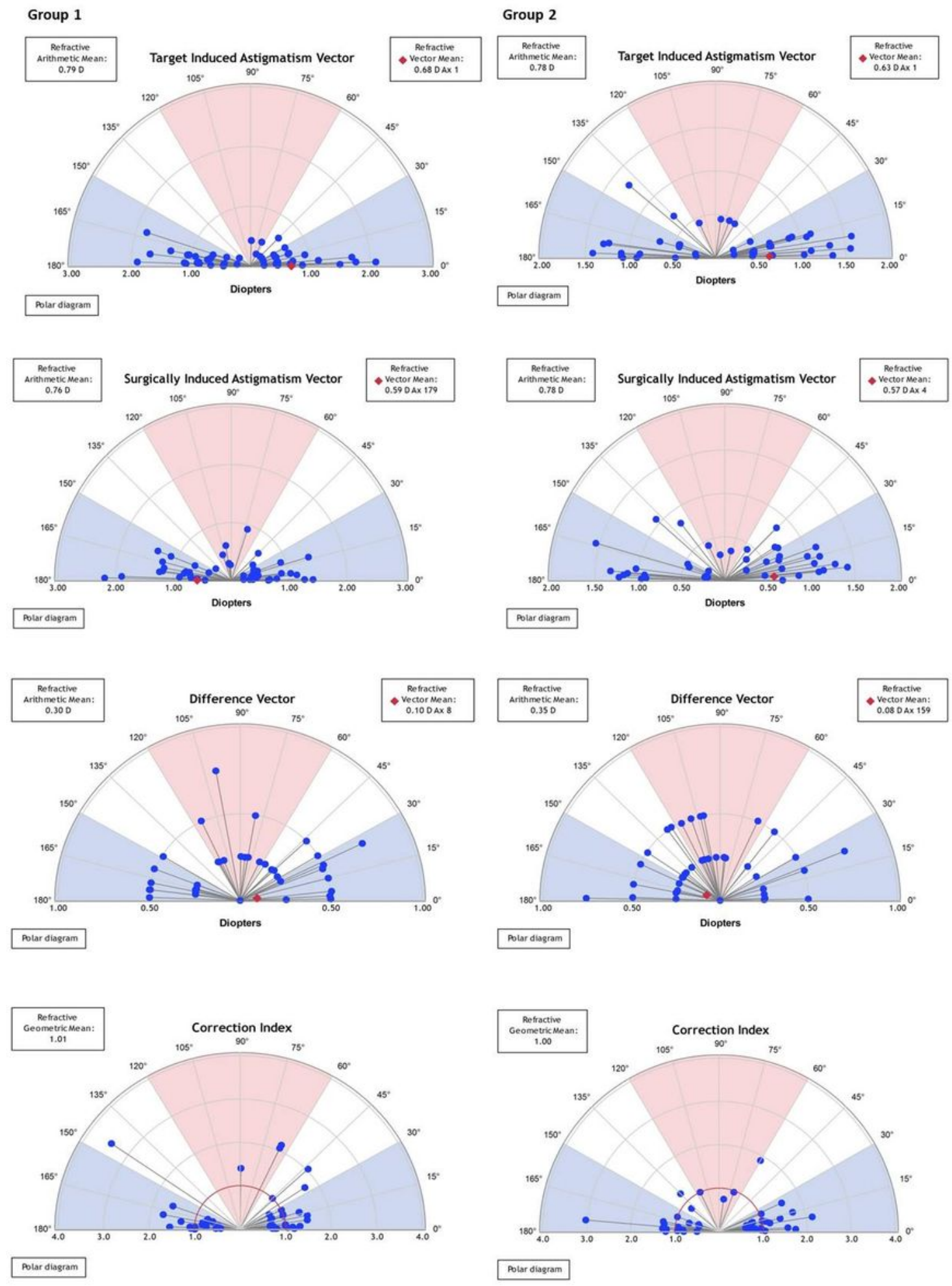

\section{Figure 1}

Single-angle polar plots depicting TIA, DV, Cl and SIA of eyes in the two group. SIA, surgically induced astigmatism; TIA, target-induced astigmatism; $\mathrm{Cl}$, correction index; DV, difference vector. 


\section{Group 1}

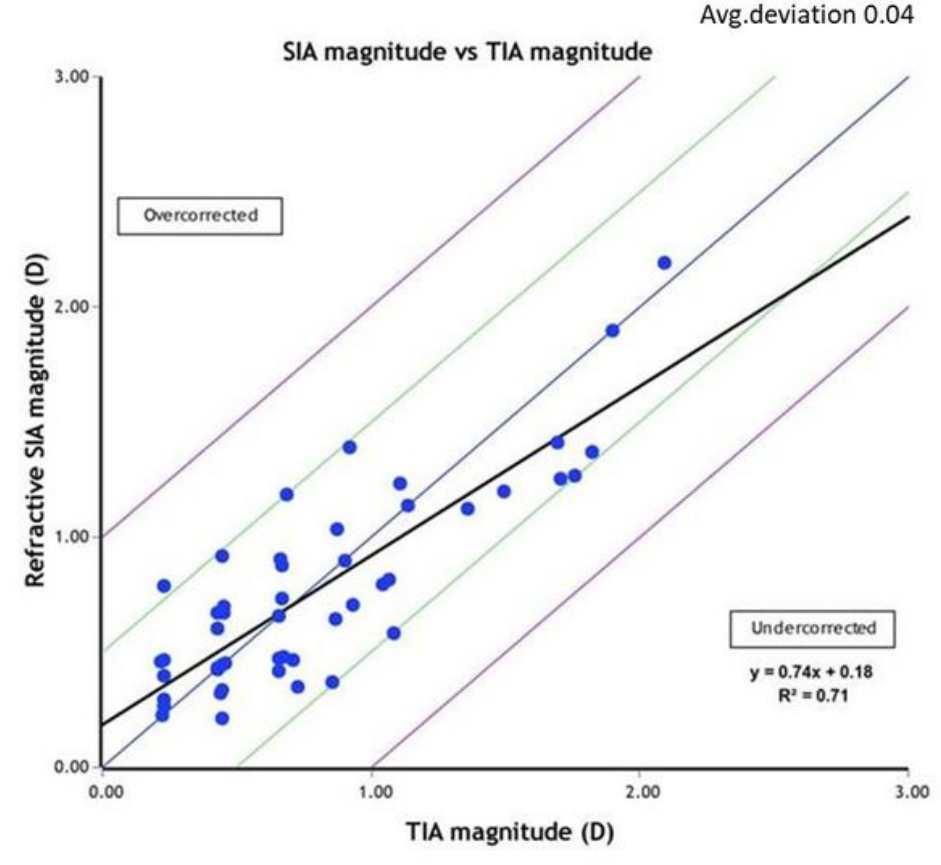

Group 2

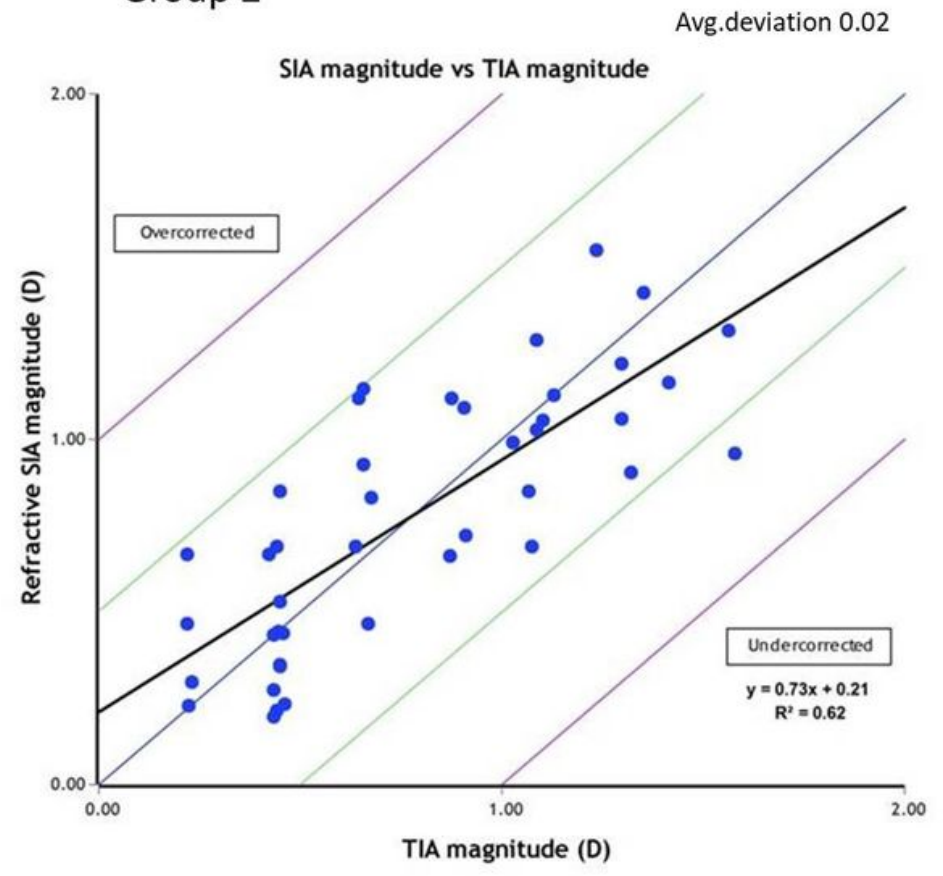

\section{Figure 2}

Surgically induced astigmatism vector versus target induced astigmatism vector in diopters (D) after small-incision lenticule extraction with a $120^{\circ}$ (Group 1 ) and $90^{\circ}$ (Group 2) cap side-cut. Above the blue line in the middle is overcorrection and below is undercorrection. The black line indicates the outcome of linear regression analysis. 